J. Lake Sci.(湖泊科学), 2009, 21(6): 879-884 http://www.jlakes.org. E-mail: jlakes@niglas.ac.cn (C)2009 by Journal of Lake Sciences

\title{
乌梁素海水体透明度分布及影响因子相关分析
}

\author{
张晓晶 ${ }^{1}$, 李畅游 ${ }^{1 * *}$, 贾克力 ${ }^{1}$, 鸟铁梅 ${ }^{2}$, 李卫平 ${ }^{1}$ \\ (1: 内蒙古农业大学水利与土木建筑工程学院, 呼和浩特 010018) \\ (2: 包头市供水总公司管网工程部, 包头 014030)
}

摘 要: 根据 2006-2008年间 5-10月对乌梁素海的连续监测资料, 分析了乌梁素海水体透明度的时空分布状况和季节变化规律, 对影响透明度的 5 个理化因子, 包括浊度、悬浮物、叶绿素 $\mathrm{a} 、$ 氮磷比和 $\mathrm{pH}$ 值进行相关分析. 三年内有监测资料的月份中, 乌 梁素海水体透明度变化范围在 $0.33-1.62 \mathrm{~m}$, 平均值为 $0.93 \mathrm{~m}$, 透明度分布的总体趋势是芦苇区及靠近芦苇区较低, 西南端开阔 水面区较高. 从相关分析结果来看, 浊度是乌梁素海水体透明度的主要影响因素, 其与透明度的关系是 $S D=1.489 x^{-0.471}(R=0.83$, $N=100, P<0.0001)$; 悬浮物是乌梁素海水体透明度的直接影响者, 与透明度的关系是 $S^{1 / 4}=-3.948 \ln S D+12.055(R=0.65, N=100, P$ $<0.0001) ; \mathrm{pH}$ 值和 N/P 对透明度的影响是间接的.

关键词: 乌梁素海; 透明度; 浊度; 悬浮物; 相关分析

\section{Spatial-temporal changes in water transparency and its impact factors in Lake Wuliangsuhai}

\author{
ZHANG Xiaojing ${ }^{1}$, LI Changyou ${ }^{1}$, JIA Keli ${ }^{1}$, WU Tiemei ${ }^{2}$ \& LI Weiping ${ }^{1}$ \\ (1: College of Water Conservancy and Civil Engineering Inner Mongolia Agricultural University, Huhhot 010018, P.R.China) \\ (2: Baotou Pipeline Engineering Department of Water Supply Corporation, Baotou 014030, P.R.China)
}

Abstract: The spatial distribution, temporal changes of water transparency and relationship between transparency and turbidity, suspended substance, chlorophyll-a, radio of total nitrogen and total phosphate, pH were analyzed based on monthly (May-October) monitoring data in Lake Wuliangsuhai from 2006 to 2008. The results indicated that the water transparency in Lake Wuliangsuhai in 2006 to 2008 ranged from $0.33 \mathrm{~m}$ to $1.62 \mathrm{~m}$ with a mean value of $0.93 \mathrm{~m}$, and the distribution trend of transparency took on increasing from the northeast to the southwest. The correlation analysis results showed that turbidity and the amount of suspended substances are two significant factors that affected the transparency. Their regression functions can be represented as $S D=1.489 x^{-0.471}(R=0.83$, $N=100, P<0.0001)$ and $S^{1 / 4}=-3.948 \ln S D+12.055(R=0.65, N=100, P<0.0001)$ respectively.

Keywords: Lake Wuliangsuhai; water transparency; turbidity; suspended substance; correlation analysis

湖水透明度是描述湖泊光学的一个重要参数, 也是评价湖泊富营养化的一个重要指标. 水体透明度 是指水面可以隐约观察到塞氏盘(Secchi Disc)时，湖面到塞氏盘之间的距离. 透明度能较直观的反映出湖 水清澈和混浊程度, 其测定方法简便易行, 因而成为湖泊常规调查中一项基本观测项目 ${ }^{[1]}$. 水体透明度 直接影响到水生植物的初级生产力状况，与太阳辐射、湖水的理化性质、悬浮物组成和含量以及气象状 况等有着密切关系.

乌梁素海位于内蒙古自治区巴彦淖尔市乌拉特前旗境内, 是内蒙古河套灌区排灌水系的重要组成部

* 国家自然科学基金项目(50569002, 50669004)、内蒙古自然科学基金重点项目(200711020604)、内蒙古自治区水利厅重 点支持项目(20080105)和内蒙古自治区“十一五”科技攻关项目联合资助. 2008-12-31 收稿; 2009-04-21 收修改稿. 张晓 晶, 女, 1983 年生, 硕士研究生; E-mail: xiaojingzhang1983@yahoo.com.cn.

** 通讯作者; E-mail: nndlichangyou@163.com. 
分，处于黄河河套平原的末端，属黄河内蒙段最大的湖泊. 湖区介于 $40^{\circ} 36^{\prime}-41^{\circ} 03^{\prime} \mathrm{N}$ 和 $108^{\circ} 43^{\prime}-108^{\circ} 57^{\prime} \mathrm{E}$, 南北长约 35- $40 \mathrm{~km}$, 东西宽约 5 $-10 \mathrm{~km}$, 湖面平均高程为 $1018.5 \mathrm{~m}$, 湖泊容量为 $2.5 \times 10^{8}-3 \times 10^{8} \mathrm{~m}^{3}$, 乌梁素 海多数区域的湖水深度在 $0.5-2.5 \mathrm{~m}$ 之间, 最大水深为 $3 \mathrm{~m}$, 平均水深约为 $1 \mathrm{~m}$. 此外, 乌梁素海地处蒙新高 原湖区, 冬季有较长结冰期, 从而使该研究区透明度的季节变化具有一定的特殊性. 冬季水生生物繁殖 缓慢甚至停止, 湖泊水动力情况处于稳定状态, 此时的透明度基本不发生变化, 同时采样工作比较困难, 所以对于乌梁素海全年监测的采样时间主要集中在每年的 5-10月.

本文根据 2006-2008 年间 5-10 月对乌梁素海的逐月监测资料, 应用 SPSS 统计分析软件, 分析了乌 梁素海水体透明度的时空分布状况和季节变化规律, 讨论了透明度与浊度、悬浮物、叶绿素 a、N/P、pH 值、水温及 $\mathrm{COD}_{\mathrm{Cr}}$ 间的相互关系, 并求出透明度与浊度及悬浮物的定量关系, 从而揭示了乌梁素海水体 透明度的分布特征及主要影响因素.

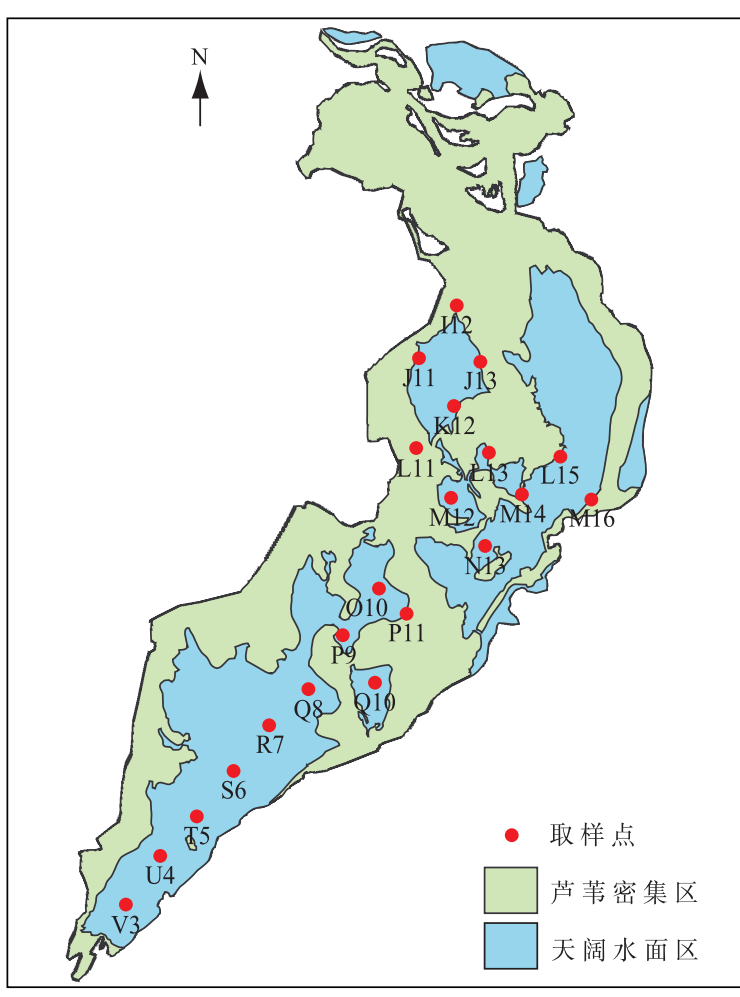

图 1 乌梁素海采样点分布

Fig.1 Locations of sampling sites in Lake Wuliangsuhai

\section{1 采样与测定方法}

\section{1 采样点设置}

将乌梁素海在空间上以 $2 \mathrm{~km} \times 2 \mathrm{~km}$ 的正 方形网格剖分, 利用网格的交点, 以梅花形 布置水样监测点. 由于夏季水生植物生长茂 盛, 芦苇密集, 部分区域几乎被水草所覆盖, 有些取样点未能到达, 透明度有连续监测数 据的点共 20 个(图 1). 监测点位置利用 GPS 定位, 取样时间为每月中旬.

\section{2 测定方法}

透明度(SD)用自制塞氏盘测定, 悬浮物 (SS)的测定采用重量法, 叶绿素 a 含量(Chl.a) 的测定用丙酮萃取分光光度计法, 浊度用哈 纳公司 LP2000-11 型的浊度仪测定, $\mathrm{pH}$ 值用 德国生产的 WTW 系列 Multi 340i 型号的便 携式手提多参数计现场测定, 水温(WT)由哈 纳公司 HI9060 型的温度测定仪现场测定, 总磷 $(\mathrm{TP})$ 、总氮 $(\mathrm{TN}) 、 \mathrm{COD}_{\mathrm{Cr}}$ 的测定参照 《水 和废水监测分析方法 $\rangle^{[2]}$ 的方法进行.

\section{2 结果与分析}

\section{1 透明度的区域分布和季节变化}

2006-2008年 5-10月各样点的年平均值 的变化趋势(图 2)可看出, 乌梁素海水体透明度变化范围在 0.33-1.62m, 空间上由北向南透明度逐渐增大, 全湖 3 年平均值为 $0.93 \mathrm{~m}$. 以时间为恒量尺度, 2006 年全湖的透明度最低，为 $0.78 \mathrm{~m}, 2008$ 年全湖的透明 度最高, 为 $1.03 \mathrm{~m}$.

此外，透明度的大小是相对的概念，其值的高低需以水深作参照. 2006-2008 年间乌梁素海不同水深 的各采样点透明度平均值的变化情况(图 3)说明，位于排干人口处的 J11 点及养殖区的 L11 点，有大量的 营养盐排人，富营养化程度很高 ${ }^{[3]}$ ，且这两点的平均水深分别为 $0.83 \mathrm{~m} 、 1.22 \mathrm{~m}$, 因而透明度很低, 分别为 $0.32 \mathrm{~m} 、 0.44 \mathrm{~m}$, 整体看湖区北部(I12-N13)水质差、悬浮物多、水体浑浊. 而处于南部的 $\mathrm{O} 10-\mathrm{V} 3$ 点 3 年 内的透明度平均值均高于其它采样点, 部分点则清澈见底, 其中 V3 点透明度的平均值最高, 为 $1.84 \mathrm{~m}$, 该点的水深为 $2.09 \mathrm{~m}$, 对于水深分别为 $1.27 \mathrm{~m}$ 和 $1.15 \mathrm{~m}$ 的 P9、Q8 点, 其透明度值相对较高, 分别为 $1.1 \mathrm{~m} 、$ 0.98m. 主要原因是这些点处于乌梁素海的西南端, 在经过中部密集芦苇和水草的吸附净化等作用后, 使水 
中的悬浮态和胶体状物质大大减少, 水质明显好转, 透明度增加. 综上所述, 对于西南端的部分透明度较低 的点, 应与北部的低值点区别对待, 水深限制了透明度的测定, 不能由此透明度来衡量水质的优劣.

从 2006-2008 年 5-10月对乌梁素海的连续监测数据中, 选取代表不同季节的 3个月份的透明度值进 行比较. 不同年份同一月份各采样点取均值后的透明度季节变化总趋势是秋季最大 $(1.12 \mathrm{~m})$, 春季次之 $(0.88 \mathrm{~m})$, 夏季最小 $(0.72 \mathrm{~m})$, 但季节变化不明显(图 4). 5 月 I12-M14 点的透明度为全年最小值, 在 $0.5 \mathrm{~m}$ 左 右变化, 而 S6-V3 点达到全年最高值, 其中 V3 点为 $2.21 \mathrm{~m} .10$ 月除了 S6-V3 点外, 其它各采样点的透明 度均为全年最高. 8 月份芦苇和水草生长最为茂盛, 部分采样点 (Q10、R7、U4)被大面积的水草覆盖, 无 法进行测量, 并且 S6、T5、V3 点的透明度为全年最低值. 春、夏季, 正值藻类大量暴发的季节, 因此 8 月份 $\mathrm{N} 13$ 点的透明度较低 ${ }^{[5-6]}$.

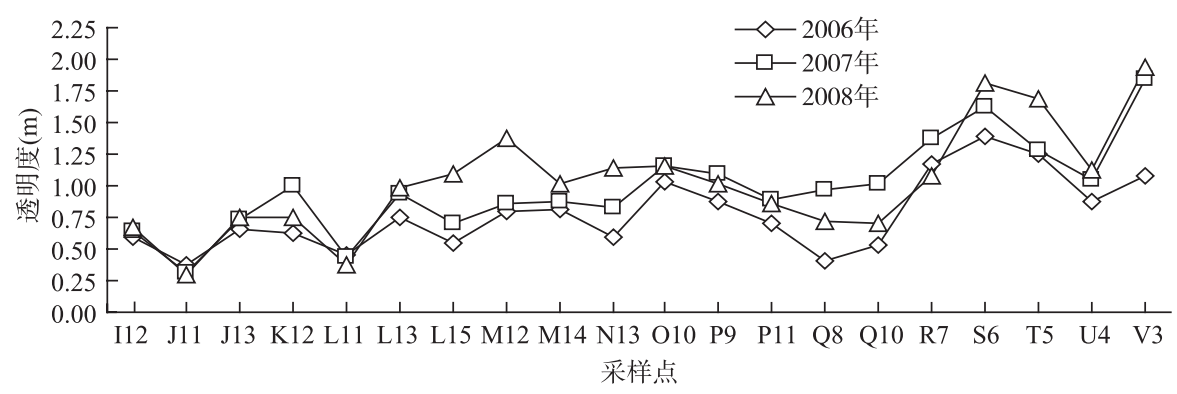

图 2 2006-2008 乌梁素海各采样点透明度年平均值的变化

Fig.2 The annually variation of water transparency in every sampling sites of Lake Wuliangsuhai during 2006-2008

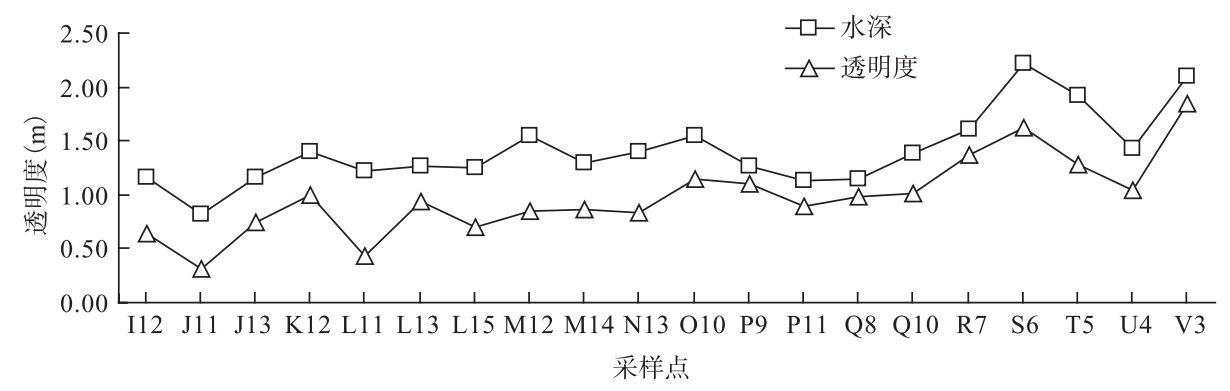

图 3 乌梁素海不同水深的各采样点透明度平均值的变化

Fig.3 The variation of water transparency in every sampling sites of Lake Wuliangsuhai under different depth of water

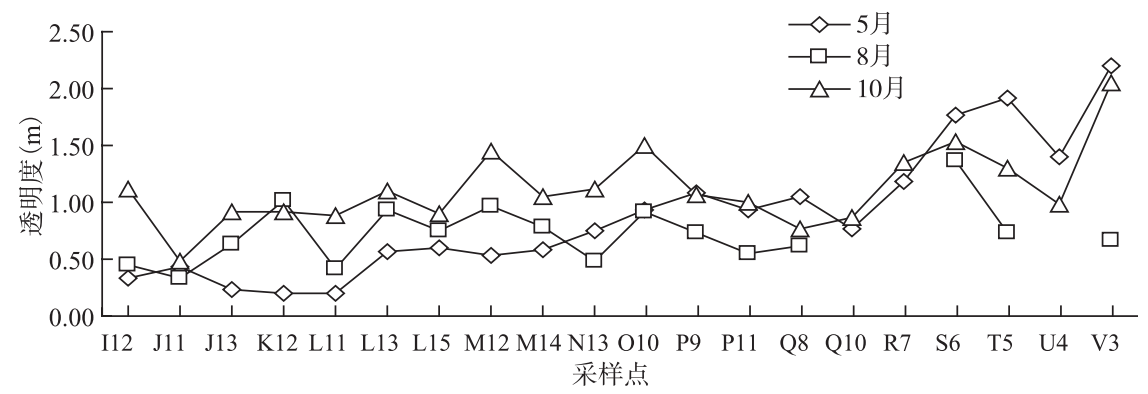

图 4 2006-2008 年乌梁素海各采样点透明度季节变化

Fig.4 Season changes of water transparency in sampling sites of Lake Wuliangsuhai during 2006-2008 


\section{2 透明度的相关分析}

对2006-2008年乌梁素海各采样点透明度及其它相关理化因子进行了两两相关性研究, 其Pearson相 关系数及其双尾检验结果见表1. 乌梁素海透明度与浊度、叶绿素a、pH值、N/P、悬浮物、 $\mathrm{COD}_{\mathrm{Cr}}$ 和水温 之间的相关关系(表1)表明, 浊度、叶绿素 $\mathrm{a}$ 与透明度呈极显著负相关, 其相关系数为 -0.535 和 $-0.304, \mathrm{pH}$ 值、 $\mathrm{N} / \mathrm{P}$ 与透明度呈极显著相关, 其相关系数为 0.310 和 0.288 , 悬浮物与透明度呈显著负相关, 其相关系数 为 -0.250 , 说明影响乌梁素海透明度的关键因子分别为浊度、叶绿素 $\mathrm{a} 、 \mathrm{pH}$ 值、 N/P、悬浮物.

表 1 乌梁素海透明度与其它影响因子的相关系数及检验结果

Tab.1 Correlation coefficients between water transparency and some influencing factors in Lake Wuliangsuhai

\begin{tabular}{cccccccc}
\hline 项目 & 浊度 & $\mathrm{SS}$ & $\mathrm{Chl} . \mathrm{a}$ & $\mathrm{pH}$ & $\mathrm{N} / \mathrm{P}$ & $\mathrm{COD}_{\mathrm{Cr}}$ & $\mathrm{WT}$ \\
\hline $\mathrm{SD}$ & $-0.535^{* *}$ & $-0.250^{*}$ & $-0.304^{* *}$ & $0.310^{* *}$ & $0.288^{* * *}$ & -0.163 & -0.086 \\
\hline
\end{tabular}

*表示 $P<0.05$ 显著相关, **表示 $P<0.01$ 极显著相关.

\section{3 透明度的影响因素分析}

2.3.1 浊度对透明度的影响 浊度是由无机质和有机质的浮游物、泥土、微生物等微粒悬浮物质所引起的. 浊度的意义是当光线通过水样后, 由于水中颗粒的遮拦或散射而使光强发生变化, 其变化率可以反映水 中分散颗粒的数量. 浊度就是表示这种变化率的一种光学度量方法, 它可以使人们对水中不同大小、密 度和形状的悬浮物、胶体、浮游生物和微生物的颗粒建立数量的概念, 但它并不能直接表示水中这些分 散杂质颗粒的含量, 这是因为浊度表示的是一种光学性质, 其数值大小不仅受到水中分散颗粒数量所支 配，而且还受到水中分散颗粒大小、形状、折光系数等多种因素的影响 ${ }^{[7]}$.

透明度是描述湖水光学性质的基本参数, 其时空变化受多种因素影响, 由前面关于透明度的相关分 析得出, 浊度是乌梁素海水体透明度的主要影响因素. 透明度与浊度的关系(图 5a)可以看出, 乌梁素海水 体的透明度与浊度呈明显的反比关系，且在一定范围内呈指数递减趋势. 对乌梁素海水体中透明度和浊 度作相关性的指数曲线拟合, 得出:

$$
S D=1.489 x^{-0.471}(R=0.83, N=100, P<0.0001)
$$

式中: $S D$ 为透明度 $(\mathrm{m}) ; x$ 为浊度(度); $R$ 为相关系数; $N$ 为样本数.

2.3.2 透明度与悬浮物的关系悬浮物和浊度都是反映水中粗分散颗粒的指标, 但二者表示方法不同. 按 GB/T14415-93 中规定，水的悬浮物是指水样通过 3-4 $\mu \mathrm{m}$ 孔径的玻璃过滤器时截留物的干燥重量，再换 算成每升水中滤出物的重量, 即为悬浮物含量 ${ }^{[7]}$.

湖水透明度表示光线在湖水中的透射深度, 其大小随湖水和其中悬浮物、浮游藻类对人射光的吸收 和散射的差异而变化, 所以悬浮物的成分和含量也影响着湖水透明度的变化. 但由于本实验在测定悬浮 物时存在一定的测量误差，从相关分析的结果看，两者的相关性并非很显著. 透明度与悬浮物的关系图 (图 5b)可知, 乌梁素海水体透明度与悬浮物呈反比关系, 且呈线性递减趋势. 对乌梁素海水体中透明度 和悬浮物作相关性的线性拟合, 得出:

$$
S^{1 / 4}=-3.948 \ln S D+12.055(R=0.65, N=100, P<0.0001)
$$

式中: $S$ 为悬浮物浓度 $(\mathrm{mg} / \mathrm{L}) ; S D$ 为透明度 $(\mathrm{m}) ; R$ 为相关系数; $N$ 为样本数.

2.3.3 透明度与叶绿素 $\mathrm{a}$ 的关系 早在 20 世纪 60 年代初就有人曾提出用透明度估计海洋初级生产力, 随 后有关学者对海水透明度与叶绿素 $\mathrm{a}$ 浓度和初级生产力的相关关系进行研究, 并提出利用海水透明度估 算叶绿素 $\mathrm{a}$ 的经验公式及真光层的初级生产力 ${ }^{[9-11]}$. 2006-2008 年测得的透明度和叶绿素 $\mathrm{a}$ 浓度的关系可 看出(图 5c), 透明度与叶绿素 $\mathrm{a}$ 的关系相对比较杂乱, 波动范围较大. 当叶绿素浓度很低时, 有些透明度 很高, 而有些却很低, 但当叶绿素浓度很高时, 其透明度比较低. 叶绿素 a 含量的高低代表藻类数量的多 少, 进而影响水体的透明度, 但在像乌梁素海这样有水生高等植物的湖泊中, 尤其是近水生高等植物的 湖区, 在采样和测定藻类叶绿素 $\mathrm{a}$ 的过程中, 有时植物微小的碎屑混人其中, 造成叶绿素含量偏高. 另外, 
沉水植物与藻类争夺光和营养盐, 从而影响藻类的生长繁殖, 降低叶绿素含量, 提高水体透明度. 因此, 叶绿素 a 对透明度的影响不确定性较大, 但总体来看叶绿素 $\mathrm{a}$ 与透明度呈现明显的反比关系.
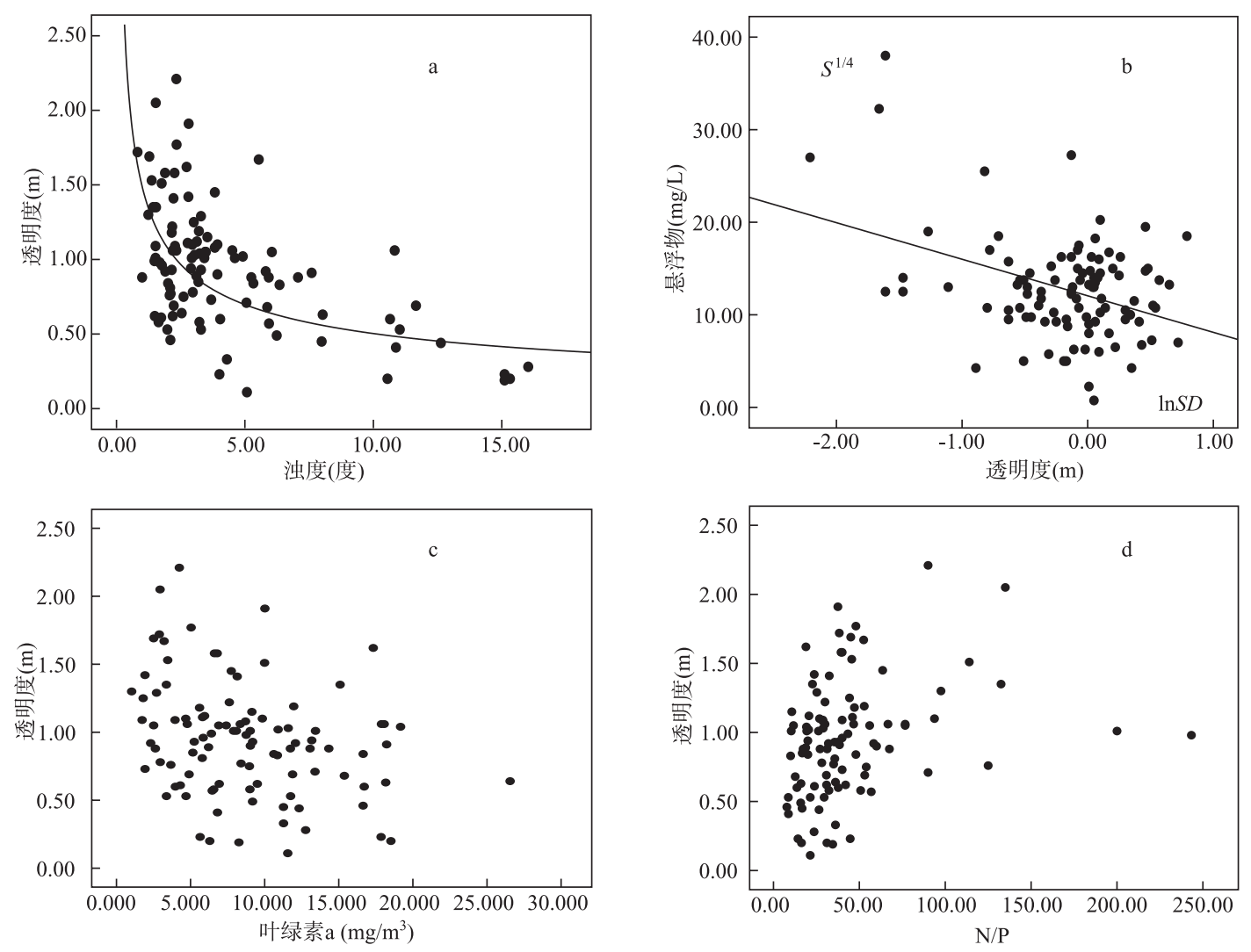

图 5 透明度与浊度(a)、悬浮物(b)、叶绿素 $a(c)$ 和 $N / P(d)$ 的关系

Fig.5 The relationship between water transparency and turbidity(a), suspended substance(b),

chlorophyll-a(c) and N/P(d)

影响水体叶绿素 a 含量的因素很多, 其中 $\mathrm{N} 、 \mathrm{P}$ 等营养盐是水体中藻类生长必不可少的因素, 它的 含量变化会影响到浮游植物的数量. 一般认为藻体内 $\mathrm{N}: \mathrm{P}$ 的质量比在 16 左右, 若高于 $16, \mathrm{P}$ 为限制因子, 若低于 $16, \mathrm{~N}$ 为限制因子. 比值相对保持在 16 左右, 藻类就能够良好生长, 若离 16 较远, 则生长相对缓 慢 ${ }^{[12]}$. 乌梁素海水体的 $\mathrm{N} / \mathrm{P}$ 大部分都高于 16 , 随着 $\mathrm{N} / \mathrm{P}$ 的增加, 透明度也呈现增加的趋势(图 $5 d$ ), 主要是 因为 N/P 值的增大, $P$ 逐渐成为限制因子的缘故.

此外, $\mathrm{pH}$ 值将直接影响水体中无机碳源的存在形式, 进而影响到水生植物光合作用速率, 是水体水 化学特征的综合反映. 一般来说, 当水体发生水华, 浮游植物大量繁殖时, $\mathrm{pH}$ 值发生明显变化, 呈现随藻 类生长而显著增高的趋势 $[13]$. 乌梁素海水体的 $\mathrm{pH}$ 值一般情况下均大于 7 , 呈偏碱性, 且变化范围比较窄. 由于乌梁素海地处北方干旱半干旱地区，其特殊的气候条件如：强蒸发、大风速、低气温等及受不同采 样点水深不同的影响，同时部分区域湖面上分布着茂密的挺水植物和沉水植物，在这些因素的综合作用 下，虽然 $\mathrm{pH}$ 与透明度存在一定的相关关系，但理论上还未能完全进行解释，有待于进一步研究.

\section{3 结论}

乌梁素海各采样点透明度的时空分布比较复杂, 但仍有一定的规律可循. 从空间分布来看, 排干人 
口处的 J11 点及养殖区的 L11 点最低, 湖西南端的开阔水面区透明度值平均较高, 尤其是 V3 点最高. 透 明度平均值季节变化的总趋势是秋季最大 $(1.12 \mathrm{~m})$, 春季次之 $(0.88 \mathrm{~m})$, 夏季最小 $(0.72 \mathrm{~m})$, 但季节变化不明 显. 夏季 N13 点有蓝藻大量繁殖, 因此该点的透明度在夏季最低.

通过对乌梁素海各采样点透明度及其它相关理化因子进行的两两相关性研究表明, 透明度与单个因 子之间的相关系数均较低, 它受多个因子的共同影响, 其中浊度、悬浮物、叶绿素 $\mathrm{a}$ 是直接因素, $\mathrm{pH}$ 值与 $\mathrm{N} / \mathrm{P}$ 则是间接因素.

浊度是乌梁素海水体透明度的主要影响因素, 和其它湖泊不同的是, 悬浮物并不是乌梁素海水体透 明度的主要影响者. 有研究表明, 悬浮物表示水中大于 $3-4 \mu \mathrm{m}$ 的悬浮颗粒含量, 而浊度则是水中大于 0.15-0.2 $\mu \mathrm{m}$ 的悬浮物及胶体颗粒含量密度的光学表示方法. 由此可推断悬浮物也是乌梁素海水体的透明 度的直接影响者, 只是其悬浮颗粒物粒径在大于 $0.15-0.2 \mu \mathrm{m}$ 范围内对透明度的影响最大.

虽然本文运用相关分析法揭示出乌梁素海水体透明度与其影响因子间的相关关系, 但要全面地揭示 各因子间的定性定量关系, 还需运用其它多学科的手段和方法, 综合考虑各种因素进行深人地研究.

\section{4 参考文献}

[1] 张运林, 秦伯强, 陈伟民等. 太湖水体透明度的分析、变化及相关分析. 海洋湖沼通报, 2003, 2: 30-36.

[2] 国家环境保护局《水和废水监测分析方法》编辑委员会. 水和废水监测分析方法(第三版). 北京: 中国环境科学出版社, 1989.

[3] 武国正, 李畅游, 张 生等. 基于主成分聚类综合分析法的湖泊富营养化评价. 环境污染与防治(网络版), 2008, (6).

[4] 李畅游, 刘廷莹, 高瑞忠等. 乌梁素海富营养化主控因子年季变化分析及综合评价. 水文, 2004, 24(3): 14-17.

[5] 张绪琴. 东中国海海水透明度分布特征. 海洋通报, 1983, 2(6): 21-24.

[6] 潘继征, 熊 飞, 李文朝等. 云南抚仙湖透明度的时空变化及影响因子分析. 湖泊科学, 2008, 20(5): 681-686.

[7] 王 峰, 闻人勤. 水的温度和悬浮物. 华东电力, 1996, 4: 27-28.

[8] 章文波，陈红艳. 实用统计分析及SPSS. 北京：人民邮电出版社, 2006.

[9] Edmondson WT. Secchi disc and Chlorophyll. Limnol and Oceanogr, 1980, 25(2): 378-379.

[10] Lorenzen MW. Use of chlorophyll-secchi disc relationship. Limnol and Oceanogr, 1980, 25(2): 371-372.

[11] Megand RO, Settles JC, Boyer HA et al. Light, secchi disc and trophic taste. Limnol and Oceanogr, 1980, 25(2): 373-377.

[12] 杨顶田, 陈伟民, 曹文熙等. 太湖梅梁湾水体透明度的影响因素分析. 上海环境科学, 2003, (增刊): 34-38.

[13] 何 俊, 谷孝鸿, 刘国峰. 东太湖水生植物及其环境的相互作用. 湖泊科学, 2008, 20(6): 790-795. 